\title{
RECURSO EDUCACIONAL DIGITAL (RED) PARA OS ANOS INICIAIS DO ENSINO FUNDAMENTAL: ASPECTOS PEDAGÓGICOS E A BASE NACIONAL COMUM CURRICULAR
}

\author{
Rayssa Araújo Hitzschky - Universidade Federal do Ceará (UFC) - \\ hitzschkyrayssa@gmail.com \\ José Aires de Castro Filho - Universidade Federal do Ceará (UFC) - \\ aires@virtual.ufc.br
}

Raquel Santiago Freire - Universidade Federal do Ceará (UFC) - freire@virtual.ufc.br

Resumo: Este estudo teve como objetivo compreender os aspectos pedagógicos envolvidos no desenvolvimento de um Recurso Educacional Digital (RED) de Língua Portuguesa, fundamentado nas habilidades da Base Nacional Comum Curricular (BNCC). De natureza qualitativa, do tipo estudo de caso, a pesquisa parte do pressuposto de que é preciso aprofundar o desenvolvimento de RED a partir de aspectos de natureza pedagógica e não somente técnica. A pesquisa evidenciou elementos importantes do desenvolvimento pedagógico, como: Alinhamento teórico, Intencionalidade pedagógica e Consistência técnico-pedagógica. Esses aspectos devem ser considerados no desenvolvimento de RED, como parte primordial do desenvolvimento de recursos.

Palavras-chave: Recurso Educacional Digital. Desenvolvimento pedagógico. Base Nacional Comum Curricular.

\section{Digital Educational Resource (DER) for the early years of Elementary Education: pedagogical aspects and the Common National Curriculum Base}

\begin{abstract}
This study aimed to understand the pedagogical aspects involved in the development of a Digital Educational Resource (DER) for Portuguese Language, based on the skills of the National Common Curricular Base (BNCC). Of qualitative nature, of the case study type, the research takes on the assumption that it is necessary to deepen the development of DER from aspects of pedagogical nature and not only technical. The research showed important elements of pedagogical development, such as: Theoretical alignment, Pedagogical intentionality and Technical-pedagogical consistency. Such aspects should be taken into consideration in the development of resources.
\end{abstract}

Keywords: Digital Educational Resource. Pedagogical development. Common National Curriculum Base.

\section{INTRODUÇÃO}

Os Recursos Educacionais Digitais (RED) podem ser compreendidos como mídias que têm o potencial de apoiar ou mediar o aprendizado (Amiel; Soares, 2015) e são encontrados em repositórios digitais, como a Plataforma MEC RED ${ }^{1}$, o Núcleo de Desenvolvimento de Objetos de Aprendizagem (NOAS) ${ }^{2}$ e o Portal do Professor ${ }^{3}$.

\footnotetext{
${ }^{1}$ https://plataformaintegrada.mec.gov.br/.

$2 \mathrm{https}: / /$ www.noas.com.br/.

${ }^{3} \mathrm{http}: / /$ portaldoprofessor.mec.gov.br/index.html.
} 
Frente à homologação da Base Nacional Comum Curricular (BNCC), documento que traz as habilidades e as competências que os alunos devem atingir em suas trajetórias escolares, torna-se necessário que o desenvolvimento desses recursos se relacione às estratégias educacionais de elaboração da BNCC. Contudo, diante da literatura, percebese que algumas pesquisas que investigam o desenvolvimento de recursos digitais (Bassani et al. 2006) se limitam a falar sobre as linguagens de programação ou os softwares utilizados durante o processo. Segundo Silva et al. (2013), os modelos utilizados para o desenvolvimento dos recursos ainda possuem poucas discussões pedagógicas sobre as ações e o planejamento de desenvolvimento dos RED.

Assim, esquece-se que o projeto de um RED, antes de tudo, "precisa ser construído sob a égide de alguma teoria de aprendizagem que possa lhe conferir objetivos pedagógicos, formas de aplicação e avaliação claros" (Braga et al. 2012, p. 2), visando maximizar a qualidade pedagógica desses recursos digitais (Fernandes et al. 2009). Diante da discussão levantada, apresenta-se a seguinte questão de pesquisa: De que forma o desenvolvimento de um Recurso Educacional Digital de Língua Portuguesa pode ser concebido, a partir dos aspectos pedagógicos, para atender as habilidades da Base Nacional Comum Curricular (BNCC)?

O objetivo geral do estudo foi compreender os aspectos pedagógicos envolvidos no processo de desenvolvimento de um Recurso Educacional Digital de Língua Portuguesa, fundamentado nas habilidades da Base Nacional Comum Curricular. Como objetivos específicos, propôs-se: a) Investigar a concepção dos aspectos pedagógicos em cada uma das etapas do processo de desenvolvimento de um RED; b) Averiguar as estratégias pedagógicas adotadas durante o desenvolvimento de um RED; c) Analisar os desafios enfrentados pela equipe pedagógica ao longo do desenvolvimento de um Recurso Educacional Digital de Língua Portuguesa, com base nas habilidades da BNCC.

A pesquisa foi realizada no âmbito do projeto Mídias Digitais na Educação (MIDE), em parceria com o Ministério da Educação (MEC). Ao final do desenvolvimento do recurso intitulado Revista Digital da Criança, ele foi disponibilizado na Plataforma MEC RED. A investigação busca enriquecer o conhecimento que envolve $o$ desenvolvimento de RED em relação aos aspectos pedagógicos, buscando apresentar achados e considerações significativas para a elaboração de recursos educacionais digitais. Os desafios de natureza pedagógica, dessa forma, precisam ser discutidos ao longo do desenvolvimento de RED, de modo que as estratégias e as intenções pedagógicas sejam aprofundadas e aprimoradas.

\section{REFERENCIAL TEÓRICO}

Nesta seção, serão apresentados as principais pesquisas e os autores que discutem sobre o desenvolvimento de RED, além de documentos de referências, como a BNCC, que contribuíram para o alinhamento teórico de recursos digitais. Também será apresentada como se configura a Língua Portuguesa e a utilização de tecnologias digitais nesta área do conhecimento.

\subsection{Discussões pedagógicas sobre o desenvolvimento de RED}

Braga et al. (2012) destacam que há uma complexidade no desenvolvimento de recursos digitais e priorizam uma harmonia entre critérios pedagógicos e técnicos. No entanto, os autores afirmam que os atributos técnicos ganham destaque à medida que os pedagógicos não são tão divulgados cientificamente. Para eles, esse fenômeno gera uma falta de clareza no desenvolvimento de recursos, podendo provocar desmotivação para a 
sua utilização por professores e alunos. Por isso, durante o desenvolvimento de um RED, os aspectos pedagógicos precisam ser rigorosamente discutidos, já que são recursos de natureza educacional que impactarão a aprendizagem.

Os autores complementam, ainda, que estes processos abordam, em geral, as etapas técnicas de produção, sem considerar as necessidades do tratamento didáticopedagógicas, esquecendo-se de garantir que os RED despertem o interesse e sejam eficazes para a aprendizagem. São abordadas, em grande parte, características como acessibilidade, facilidade de instalação, portabilidade, interoperabilidade e usabilidade. No entanto, esses aspectos apresentam um viés meramente técnico, relacionados ao armazenamento, ao acesso, à interação com outros sistemas operacionais e às formas de utilização dos recursos.

O desenvolvimento de um RED, então, pode ser compreendido como o processo que envolve, segundo Fernandes et al. (2009), planejar atividades que se relacionam com os conceitos e os conteúdos curriculares, a partir da delimitação de ideias e estratégias necessárias para a concepção do recurso. De acordo com Braga et al. (2012), as estratégias pedagógicas envolvem a materialização das concepções referentes à abordagem de um conteúdo escolar e são envoltas de uma intenção pedagógica.

Uma proposta de desenvolvimento de RED que engloba aspectos pedagógicos em suas etapas foi o modelo trazido pela Rede Internacional Virtual de Educação (RIVED), um programa da Secretaria de Educação a Distância (SEED), criado em 2008. O modelo de produção pedagógica proposto pelo RIVED traz como documentos: o Design Pedagógico, o Roteiro Pedagógico e o Guia do Professor. O design pedagógico propõe os objetivos, os conteúdos a serem abordados e as orientações para as atividades. O roteiro pedagógico explica as telas, os diálogos e as ações das atividades, e o guia do professor discute as metodologias pedagógicas para as atividades, para sua melhor utilização em sala de aula.

Outro modelo de desenvolvimento de RED é a Metodologia INTERA (Inteligência em Tecnologias Educacionais e Recursos Acessíveis), concebido pela Universidade Federal do ABC (UFABC). Este modelo caracteriza-se pelo seu caráter multidisciplinar, tendo em vista que pauta o desenvolvimento dos RED na interseção entre a Engenharia de Software e os processos de produção didático-pedagógicos, mostrando um equilíbrio entre os aspectos técnicos e pedagógicos.

O desenvolvimento de um RED, portanto, deve pautar-se em objetivos pedagógicos, para que o RED não cumpra apenas uma função ilustrativa ou técnica. Desse modo, faz-se necessário compreender o desenvolvimento a partir do planejamento didático-pedagógico, para que o RED não seja visto como um elemento sem sentido no processo de ensino e de aprendizagem (Braga; Ponchio, 2015). Na seção seguinte, discute-se sobre a BNCC, a Língua Portuguesa e a relação com as tecnologias digitais.

\subsection{A Base Nacional Comum Curricular (BNCC), a Língua Portuguesa e as tecnologias digitais: diálogos e interseções}

A BNCC, homologada em 2017, é um documento normativo que traz as aprendizagens essenciais que devem ser desenvolvidas pelos estudantes em suas trajetórias escolares (Brasil, 2017). O documento divide-se em competências gerais e específicas para cada componente. O componente de Língua Portuguesa, organizado no campo de Linguagens, divide-se em práticas de linguagem, campos de atuação, objetos de conhecimento e em habilidades. As práticas de linguagem refletem as diversas práticas 
sociais construídas pelos sujeitos ao fazerem uso da língua e permeiam a oralidade, leitura/escuta, produção (escrita e multissemiótica) e análise linguística/semiótica.

O documento centra-se na concepção enunciativo-discursiva da língua, conforme os preceitos de Bakhtin (1997), interligando-se aos campos de atuação que representam as esferas da comunicação social. Para Geraldi (2015), os campos de atuação são parâmetros que norteiam a vivência das práticas de linguagem de forma mais aplicada. Os campos de atuação para os anos iniciais do Ensino Fundamental são da vida cotidiana, artístico-literário, das práticas de estudo e pesquisa e da vida pública.

Assim, a Língua Portuguesa tem como uma de suas finalidades ampliar os letramentos dos alunos, de modo que este componente potencialize a construção das capacidades e a participação nas práticas sociais construídas por meio da oralidade, da produção e por outras linguagens. Uma das práticas contemporâneas consideradas são aquelas que envolvem gêneros com tendências mais multimidiáticas. Exemplos desses gêneros são os memes, vlogs, playlists comentadas, revistas digitais e infográficos, que envolvem os alunos em "novas formas de produzir, de configurar, de disponibilizar, de replicar e de interagir" (Brasil, 2017, p. 64), em um nítido movimento de protagonismo.

Ainda de acordo com o documento, a escola não pode se manter alheia aos conteúdos que circulam na Web. Para tanto, a BNCC considera as múltiplas esferas de atividade social e os gêneros do discurso que emergem das situações sociais que tenham, como essência, a comunicação e a interação entre indivíduos, exigindo práticas de compreensão e análise de cada uma delas (Rojo; Moura, 2012).

Nesse sentido, a BNCC implica desafios para as práticas educacionais, tornandose necessário compreender que um novo perfil de aluno vem surgindo: um que cria e compartilha ativamente informações no emaranhado digital. Esse cenário cria repercussões para os desenvolvedores de recursos, para que compreendam os documentos e os fundamentos pedagógicos que devem embasar o desenvolvimento desses recursos.

\section{MATERIAL E MÉTODOS}

Nesta seção, primeiramente, o contexto da pesquisa será detalhado. Em seguida, o RED em foco, que teve o seu desenvolvimento investigado, será apresentado.

\subsection{Caracterização do tipo e do método da pesquisa}

A pesquisa teve uma abordagem qualitativa, bem como uma natureza interpretativa. Nesta abordagem, a fonte dos dados é o ambiente natural, no qual o investigador está em contato constante com os fenômenos investigados e os seus resultados (Bogdan; Biklen, 1991).

Lüdke e André (1986) ressaltam que em uma pesquisa qualitativa há a necessidade de capturar a perspectiva dos participantes. Por isso, esta pesquisa foi rica em descrições, situações e acontecimentos, advindos de documentos, observações e anotações em diários de campo, relacionadas às reuniões. A pesquisa visou a análise do desenvolvimento de um recurso de Língua Portuguesa dos anos iniciais do Ensino Fundamental, que trabalhou com o suporte revista em formato digital. No decorrer da investigação, observou-se os elementos pedagógicos que surgiram ao longo das suas etapas de desenvolvimento.

A investigação foi um estudo de caso, pois envolveu a investigação do processo de desenvolvimento de um RED específico em meio ao rol de um projeto maior, que compreendeu a concepção de outros RED de Língua Portuguesa e de Matemática.

As ações para a realização da pesquisa transcorreram-se com o acompanhamento participativo do desenvolvimento do recurso, já que a pesquisadora era integrante da 
equipe pedagógica de Língua Portuguesa. Os registros das reuniões eram escritos em um diário de campo e organizados conforme a natureza dos encontros. Após o desenvolvimento do RED, os documentos foram analisados, observando-se também o discurso dos sujeitos. Posteriormente, uma entrevista com os membros da equipe pedagógica foi realizada. Por fim, um debruçamento sobre os dados foi feito, confrontando-os com o referencial teórico e com os objetivos e, assim, categorias de análise foram propostas.

A entrevista, orientada por um roteiro previamente estruturado, foi realizada com um grupo focal, que incluiu a equipe pedagógica de Língua Portuguesa do projeto. Segundo Gondim (2003), os grupos focais permeiam interações grupais ao se discutir um tópico sugerido pelo(a) entrevistador(a), facilitador(a) da discussão. Com isso, esperouse que a pesquisa se aproximasse do seu teor qualitativo, ao investigar um caso específico de desenvolvimento de um RED e os seus aspectos pedagógicos. A seguir, o Recurso Educacional Digital da investigação será apresentado.

\subsection{O Recurso Educacional Digital (RED) investigado}

O RED Revista Digital da Criança ${ }^{4}$ trabalha com a estrutura de uma revista digital e gêneros como editorial, infográfico, entrevista e carta do leitor, buscando ampliar a percepção dos alunos sobre esses gêneros. Os gêneros estudados integram os campos de atuação das práticas de estudo e pesquisa e do campo da vida pública da BNCC.

O recurso contempla as práticas de linguagem leitura/escuta (compartilhada e autônoma) e produção (escrita e multissemiótica), conforme orientações da BNCC. O RED foi pensado para o $5^{\circ}$ ano do Ensino Fundamental, porém as habilidades consideradas foram mais abrangentes, contemplando do $3^{\circ}$ ao $5^{\circ}$ ano. O RED simula a estrutura de uma revista impressa, entretanto, contém experiências de leitura interativas, beneficiando-se do meio digital. Além disso, traz micro jogos, inspirados em revistas como Recreio $^{5}$ e Ciência Hoje das Crianças ${ }^{6}$, com o objetivo de trabalhar a interpretação textual das seções.

O recurso é dividido em seções e tem início com a capa, que é a sua tela inicial. Também traz um editorial, com a apresentação dos editores e o sumário. A seção seguinte apresenta um infográfico interativo sobre a evolução das brincadeiras infantis, com curiosidades sobre as brincadeiras: faz de conta, cabra-cega, amarelinha e games digitais. Depois, traz um caça-palavras sobre as brincadeiras apresentadas no infográfico.

A seção seguinte apresenta uma entrevista com Maria Clara, uma criança real de nove anos, sobre a produção de conteúdo digital. Após a entrevista, tem-se um jogo de cartas, cujo objetivo é relacionar perguntas e respostas sobre a entrevista. Como último bloco, o recurso traz a seção das cartas dos leitores, na qual é possível ter acesso às cartas de duas crianças fictícias que discutem uma reportagem sobre o uso de canudos descartáveis. Em seguida, o RED propõe uma atividade sobre o gênero carta do leitor. $O$ recurso é concluído com a produção de uma carta do leitor sobre algum tema da revista.

O RED foi concebido a partir de diferentes linguagens favorecidas pelo meio digital. Logo, buscou-se potencializar a compreensão, por parte dos alunos, dos gêneros

\footnotetext{
${ }^{4}$ Disponível em: http://mide-revista-digital-da-crianca.netlify.app.

5 Periódico mensal publicado, inicialmente, pela Editora Abril e, posteriormente, pela Editora Caras, que trazia conteúdos voltados para o público infanto-juvenil. A marca hoje faz parte da UOL (https://recreio.uol.com.br/).

${ }^{6}$ http://chc.org.br/.
} 
dos campos das práticas de estudo e pesquisa e da vida pública no cotidiano e a sua importância para a comunicação em sociedade.

\section{RESULTADOS E DISCUSSÃO}

Esta seção apresentará as categorias encontradas na investigação: Alinhamento teórico, Intencionalidade pedagógica e Consistência técnico-pedagógica. Antes de explicitá-las, serão apresentadas as 07 (sete) etapas de desenvolvimento do RED investigado. As etapas estiveram relacionadas aos aspectos pedagógicos investigados.

A primeira etapa, "Contextualização", consistiu da discussão das ideias iniciais do recurso, abordagens teóricas e metodológicas segundo a BNCC. Na segunda etapa, "Especificações e Storyboard", foi escrito um roteiro pedagógico, com o objetivo de descrever a narrativa, as atividades, os diálogos e os feedbacks das interações.

A terceira etapa, "Design visual", foi composta pela criação dos elementos visuais do roteiro, como ícones, tipografia, telas e personagens. A quarta etapa, "Desenvolvimento", incidiu na implementação do roteiro pedagógico. Na quinta etapa, "Guia de Orientações Didáticas", um guia do professor foi feito, visando a utilização do RED pelo professor.

Na sexta etapa, "Avaliação", o recurso e o Guia de Orientações Didáticas foram testados e revisados, buscando observar se os elementos inseridos no roteiro e no guia foram contemplados. Na sétima etapa, "Disponibilização", o RED e o Guia foram disponibilizados na Plataforma MEC RED.

\subsection{Alinhamento teórico: a concepção pedagógica de um RED em seu desenvolvimento}

O Alinhamento teórico surgiu na concepção da proposta pedagógica do RED, na etapa de "Contextualização". Diante da análise realizada, pode-se afirmar que a primeira ação para o início do desenvolvimento de um recurso é a determinação de um alinhamento teórico. Antes mesmo do início do desenvolvimento, um RED deve ser pensado de acordo com uma vertente pedagógica, com o objetivo de traçar os seus objetivos e a forma como eles serão atendidos. Essa delimitação demarca determinados aspectos teóricos que influenciam a proposta do recurso, dentre eles, as atividades, as mecânicas, os tipos de feedbacks e, até mesmo, a construção da narrativa. Assim, percebe-se que um RED não possui uma neutralidade pedagógica, posto que a sua base está amparada neste alinhamento.

A fundamentação teórica escolhida para o recurso foi a Base Nacional Comum Curricular (BNCC). Dessa forma, o recurso foi desenvolvido de acordo com os pressupostos teóricos do documento, assim como a partir dos seus elementos organizacionais, como as habilidades, os campos de atuação e as práticas de linguagem. A escolha por esse embasamento teórico caracterizou-se pela relevância da BNCC no contexto educacional, tendo em vista o seu caráter norteador para as práticas escolares.

O primeiro aspecto relacionado a esta categoria foi a construção dos seus objetivos pedagógicos, que buscaram trabalhar a leitura e a escrita de modo inter-relacionado. A finalidade foi propor que as seções de leitura do RED fossem acompanhadas de atividades de produção. Paralelamente, a equipe pedagógica optou pelos campos das práticas de estudo e pesquisa e da vida pública como uma possibilidade para a abordagem multissemiótica das práticas de linguagem leitura/escuta (compartilhada e autônoma) e 
produção (escrita e multissemiótica), para uma diversificação dos gêneros e das linguagens abordadas, de acordo com as orientações do documento.

Um segundo aspecto relacionado ao alinhamento teórico envolveu a área de conhecimento, a disciplina e o conteúdo escolhido para o recurso, abrangendo a Língua Portuguesa na BNCC. Uma das discussões foi a carga de leitura que o RED possuiria com os gêneros abordados e a decisão pela inclusão de seções próprias de uma revista, como capa e sumário, para torná-la verossímil à sua veiculação vista em sociedade. Um terceiro aspecto foi o público-alvo, pensado de acordo com o bloco organizativo da BNCC e suas habilidades. Os conhecimentos prévios considerados foram definidos com base nas habilidades da BNCC trabalhadas em anos anteriores e que contemplavam os gêneros trabalhados no recurso.

Esta categoria também englobou a relevância do conteúdo, enfatizando a importância de se trabalhar a revista como um suporte para outros gêneros. Assim, destacou-se a presença de gêneros como editorial, infográfico, entrevista e carta do leitor para situações de comunicação. Entendendo-se que estes gêneros são utilizados comumente em práticas letradas, é oportuno estudá-los, alinhando-os às habilidades previstas na BNCC. Além disso, ponderou-se a importância de estudo dos gêneros textuais enquanto instâncias comunicativas. Nesse sentido, a proposta do RED mostrouse bem sustentada na BNCC, pois considerou a leitura e a escrita de forma contextualizada aos seus usos sociais e não de forma isolada.

Por fim, observou-se que o alinhamento teórico de desenvolvimento do RED só foi possível devido o planejamento prévio dos conceitos e dos conteúdos curriculares. Assim, para a apropriação e inserção de um alinhamento teórico, percebe-se que estudos preliminares são necessários, a fim de buscar orientações que nortearão 0 desenvolvimento do RED.

\subsection{Intencionalidade pedagógica: estratégias e tomadas de decisão}

A Intencionalidade pedagógica foi percebida nas etapas de "Especificações e Storyboard" e "Design visual". Verificou-se que esta intencionalidade, a princípio, envolveu a própria escolha da equipe pedagógica pela escrita de um roteiro ao invés de um storyboard. Essa decisão ressalta que, para a equipe, a estrutura de um roteiro atendia melhor as demandas específicas para a proposta do RED, dentre elas, o detalhamento das atividades.

O primeiro aspecto do roteiro relacionado à intencionalidade pedagógica foram as seções dedicadas à capa, ao sumário e ao editorial, como forma de relacionar as suas identidades visuais à de uma revista digital, buscando tornar o recurso verossímil ao suporte. O mesmo ocorreu com a escolha dos gêneros tratados no RED, como entrevista animada e infográfico, nos quais estes pudessem criar interações e simulações que os recursos midiáticos oportunizam.

A forma de organização do infográfico conteve uma intencionalidade pedagógica, pois sua estruturação buscou trazer as informações, divididas pelas brincadeiras, de forma objetiva e fluida, seguindo um padrão de apresentação: surgimento, forma de brincar e curiosidades. Outro aspecto do infográfico é que a escolha das brincadeiras foi feita a partir de uma representatividade histórica e cultural.

Posteriormente, o RED traz um jogo de caça-palavras sobre as brincadeiras do infográfico. Verificou-se que esta inserção teve um propósito educacional bem definido, pois relacionou-se com as brincadeiras do infográfico. Além disso, a mecânica escolhida emite retornos visuais que integram o aluno durante a resolução da atividade. 
A seção da entrevista teve uma intencionalidade pedagógica quando organizada pelas características do gênero, a partir da transposição exata da fala do entrevistado, por perguntas curtas e pela divisão da entrevista em uma ordem gradual de perguntas e respostas. Além disso, o tema da entrevista, que foi a produção de conteúdo digital feita por crianças, retrata a temática da revista, estabelecendo uma convergência da seção com os demais assuntos tratados no recurso.

A seção das cartas dos leitores foi desenvolvida priorizando-se uma leitura fluida, com a apresentação de textos curtos e o trabalho de um tema pertinente (o uso de canudos descartáveis), trazendo opiniões distintas sobre o assunto. As cartas dos leitores foram escritas com base nas características e na formatação do gênero (local, data, cumprimento inicial, despedida) e a partir de imagens fictícias dos leitores, entre 8 e 10 anos.

Após a leitura das cartas dos leitores, o recurso apresenta uma atividade lacunada que traz informações específicas sobre o gênero carta do leitor. A intencionalidade pedagógica desta atividade foi propor a identificação e a revisão do gênero, de forma mais dinâmica, menos cansativa e evitando uma carga excessiva de textos por tela. $\mathrm{Na}$ atividade da carta do leitor, a equipe pedagógica decidiu inserir um layout para a carta, no entanto, optou por não acrescentar os campos pré-determinados aos espaços correspondentes, tendo em vista que essa ação subestimaria a capacidade de percepção e compreensão dos alunos para a produção. Esta intencionalidade pedagógica destaca a importância da percepção do aluno e a importância da presença do professor como sujeito que mediará a produção escrita dos estudantes, guiando-os para a apropriação do gênero.

Um aspecto de design visual que apresentou uma intencionalidade pedagógica foi a formatação do jogo de caça-palavras. A equipe pedagógica sugeriu a inserção de uma imagem na atividade, para que a seção não fosse apenas textual. Logo, observa-se que o design visual não se constituiu apenas um elemento estético, mas serviu a um propósito pedagógico, a fim de contemplar os aspectos visuais e textuais.

Igualmente, o jogo de correspondência de cartas teve uma intencionalidade pedagógica em sua formatação e mecânica. De início, a disposição das cartas não estava bem definida no roteiro e os designers apresentaram três propostas. A equipe pedagógica escolheu a proposta na qual as cartas de respostas estariam em um monte e seriam arrastadas para os espaços correspondentes das cartas de perguntas, pois se aproximava da proposta de correlação da atividade, além de ser mais explicativa e intuitiva. Um tutorial foi inserido na seção, de forma que a mecânica do jogo fosse explicada, demonstrando que a equipe buscou antecipar possíveis dúvidas dos estudantes.

A partir da análise das etapas do desenvolvimento, constata-se que a decisão pelos conteúdos abordados em cada seção, em grande parte, envolveu uma intencionalidade pedagógica que direcionou as tomadas de decisão e as estratégias para a escrita do roteiro. Observa-se, ainda, que a intencionalidade pedagógica incluiu a forma de organização dos conteúdos, tendo em vista que essa estruturação influenciaria diretamente os objetivos educacionais traçados para as atividades e para a proposta do recurso.

Além disso, houve uma preocupação com os elementos visuais, que refletiu a busca pela abordagem autêntica dos gêneros trabalhados no RED. Desse modo, o design visual esteve diretamente vinculado à proposta pedagógica do recurso, pois trabalhou em função dela para que as ilustrações e os demais elementos do recurso fossem criados.

\subsection{Consistência técnico-pedagógica e a revisão final do recurso}

A categoria Consistência técnico-pedagógica foi observada durante a etapa de "Avaliação" e visou o refinamento pedagógico e técnico do RED, conforme discussões estabelecidas no processo. O primeiro aspecto da revisão do recurso que evidenciou esta 
categoria foi visto no infográfico e na entrevista. A equipe pedagógica assinalou que a tipografia utilizada nestas seções dificultava a leitura dos textos, sendo difícil identificar os acentos, as vírgulas e os pontos finais, prejudicando a leitura do texto em geral. Observa-se que esta mudança de tipografia, caso não realizada, incidiria diretamente na qualidade da leitura e na compreensão das seções pelo aluno, alterando os objetivos pedagógicos do RED.

Ainda na seção da entrevista, a equipe pedagógica observou que os balões de fala da entrevistadora e entrevistada estavam em branco, sem apresentar uma função aplicada. Após essa observação, os designers inseriram as perguntas e as respostas textualmente nos balões, permitindo que o fluxo da entrevista fosse acompanhado. Essa percepção comprova a influência de uma consistência técnico-pedagógica durante a avaliação do RED, pois a equipe retomou a proposta da seção, de envolver a leitura, a interpretação e a compreensão do gênero, paralelamente à indicação de melhorias para a versão final do recurso.

Após a inserção dos textos nos balões, a equipe pedagógica observou que os textos escritos não ficaram totalmente espelhados às falas da entrevistadora e da entrevistada e, assim, os programadores alteraram os textos conforme os áudios. Ainda nessa revisão, a equipe pedagógica apontou que a opção "reler entrevista" não estava ativa.

Um outro aspecto relativo à Consistência técnico-pedagógica foi averiguado na atividade lacunada relacionada à seção das cartas dos leitores. A equipe de Língua Portuguesa percebeu uma incoerência pedagógica na terceira questão da atividade, na qual esta compreendia duas opções de resposta, "opinião" e "sugestão", para duas lacunas. A equipe pedagógica observou que as duas opções poderiam ocasionar confusões quanto à resposta correta para a sentença, pois ambas eram aceitáveis. Logo, a palavra "opinião" foi mantida e a palavra "sugestão" foi substituída por "discrição", a qual não pode ser considerada correta na atividade.

Conclui-se que a Consistência técnico-pedagógica buscou dar um fechamento ao desenvolvimento do RED, dando-lhe uma coerência pedagógica e técnica discutida desde o princípio do processo. Nesse sentido, observa-se que o desenvolvimento buscou preservar, ao longo de suas etapas, a ideia pedagógica do RED, por meio de ajustes, visando o seu aprimoramento. Esta Consistência técnico-pedagógica apresentou um movimento necessário, realçando a necessidade dessa ação quando se visa o refinamento do produto definitivo.

\section{CONCLUSÕES}

A análise dos dados evidenciou aspectos pedagógicos relevantes no desenvolvimento. Estes aspectos refletiram categorias que nortearam o processo, envolvendo a fundamentação teórica que embasou o RED, as intencionalidades pedagógicas, que orientaram as escolhas e a elaboração da estrutura do recurso como um todo, aliadas ao design, culminando em um aspecto de fechamento do desenvolvimento.

As categorias também nortearam o desenvolvimento para a concepção e consolidação da proposta central do recurso, conforme funções distintas em cada uma das etapas, como também refletiram os desafios enfrentados pela equipe pedagógica ao longo do desenvolvimento, mostrando que o processo foi dialógico e inter-relacional.

Assim sendo, considera-se que a pesquisa trouxe contribuições quando se discute e demonstra a presença dos elementos educacionais no desenvolvimento. Apesar do estudo apresentar um caso específico de elaboração, ele pode proporcionar caminhos teóricos e metodológicos para outros processos de desenvolvimento que desejem ter 
referências para a vertente pedagógica. Como estudos futuros, será realizada a validação do recurso, de modo a verificar a sua efetividade pedagógica em sala de aula.

\section{REFERÊNCIAS BIBLIOGRÁFICAS}

AMIEL, T.; SOARES, T. C. O contexto da abertura: recursos educacionais abertos, cibercultura e tensões. Em Aberto, Brasília, v. 28, n. 94, 2015, p. 109-122, jul./dez.

BAKHTIN, M. M. Estética da criação verbal. $2^{\circ}$. ed. São Paulo: Martins Fontes, 1997, $421 \mathrm{p}$.

BASSANI, P. B. S.; PASSERINO, L. M.; PASQUALOTTI, P. R.; RITZEL, M. I. Em busca de uma proposta metodológica para o desenvolvimento de software educativo colaborativo. Revista Novas Tecnologias na Educação, 4 (1), 2006, 1-10.

BRAGA, J.; DOTTA, S.; PIMENTEL, E.; STRANSKY, B. Desafios para o desenvolvimento de objetos de aprendizagem reutilizáveis e de qualidade. Workshop de Desafios da Computação aplicada à Educação (Desafie), Paraná, 2012.

BRAGA, J.; PONCHIO, R. Contextualização: o início da concepção e um novo objeto de aprendizagem. In.: BRAGA, J. (Org.). Objetos de Aprendizagem: metodologia de desenvolvimento. Volume 2, Santo André: Editora da UFABC, 2015. 163p.

BRASIL. Ministério da Educação. Base Nacional Comum Curricular. Brasília: MEC/ Secretaria de Educação Fundamental, 2017.

BOGDAN, R.; BIKLEN, S. Investigação qualitativa em educação: uma introdução à teoria e aos métodos. Portugal: Porto, 1991.336p.

FERNANDES, A. C.; FREIRE, R. S.; SOUZA, M. F.; MEDEIROS, M. D.; CASTROFILHO, J. A. Modelo para qualidade de objetos de aprendizagem: da sua concepção ao uso em sala de aula. Anais do XX Simpósio Brasileiro de Informática na Educação. Santa Catarina, 2009.

GERALDI, J. W. O ensino de língua portuguesa e a Base Nacional Comum Curricular. Revista Retratos da Escola, Brasília, v. 9, n. 17, 2015, p. 381-396, jul./dez.

GONDIM, S. M. G. Grupos focais como técnica de investigação qualitativa: desafios metodológicos. Paidéia, 2003. p. 149-161. Disponível em: $<$ http://www.scielo.br/pdf/paideia/v12n24/04>. Acesso em 22 jun. 2020.

LÜDKE, M.; ANDRÉ, M. E. D. A. Abordagens qualitativas de pesquisa: a pesquisa etnográfica e o estudo de caso. In.: LÜDKE, M.; ANDRÉ, M. E. D. A. (Org.). Pesquisa em Educação: Abordagens Qualitativas. São Paulo: EPU, 1986.

RECREIO (Revista). In: Wikipédia, a enciclopédia livre, 2020. Flórida: Wikimedia Foundation. Disponível em:

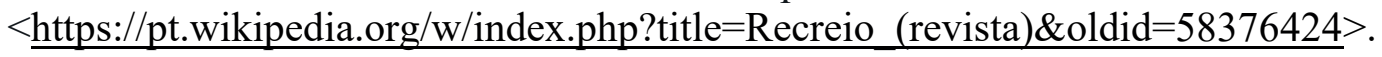
Acesso em: 01 ago. 2020.

ROJO, R. H. L; MOURA, E. (Orgs.). Multiletramentos na escola. Parábola Editorial: São Paulo, 2012. 264p.

SILVA, T. R. da; LIMA, R. W. de; MESQUITA, H. H. O.; MARQUES, C. K. M. O uso de ferramentas pedagógicas no desenvolvimento de Objetos de Aprendizagem. Revista de Informática Aplicada, Volume 9, Número 1, 2013. 